\title{
FIELD BLOCK FOR INGUINAL HERNIA REPAIR- A CLINICAL STUDY
}

Shivakumar K.P, Mahantesha. J. Sharma, Arunkumar Ajjappa
1. Assistant Professor, Department of Anaesthesia, SSIMS \& RC. Davangere, Karnataka.
2. Professor, Department of Anaesthesia, J. J. M. Medical College. Davangere, Karnataka.
3. Professor, Department of Anaesthesia, SSIMS \& RC. Davangere, Karnataka.

\section{CORRESPONDING AUTHOR}

Dr. Shivakumar K.P

\#2051, 2nd Main 2nd Cross,

Behind Modi Compound,

MCC 'A' Block, Davangere, Karnataka.

E-mail: drshivukumarkp@gmail.com

Ph: 00919902006367

ABSTRACT: BACKGROUND AND OBJECTIVES: Present clinical study was conducted to evaluate advantages of field block for inguinal hernia repair, with respect to duration and quality of analgesia, haemodynamic stability, and speed of recovery by using $1 \%$ lidocaine with adrenaline. METHODS: Study was conducted on 50 patients posted for elective inguinal hernia repair. Field block was instituted with $1 \%$ lidocaine with adrenaline with mean volume of 35.48 $\mathrm{ml}$ to block ilioinguinal, iliohypogastric, genital branch of genitofemoral nerve with subcutaneous infiltration. Patients were observed for duration and quality of analgesia. Haemodynamic stability with PR, systolic and diastolic BP. Post anaesthesia recovery was assessed by using "criteria for fast track eligibility for ambulatory anaesthesia" after the surgery. Duration of analgesia was assessed with subjective complaint of pain (duration of onset of analgesia till the subjective complaint of pain). RESULTS: In the present study, the quality of analgesia was excellent in $72 \%$ of cases, good in $16 \%$, fair in $8 \%$ and poor in $4 \%$. The mean duration of analgesia was $201.02 \mathrm{~min}(160 \mathrm{~min}$ to $280 \mathrm{~min})$. All patients were haemodynamically stable throughout the surgery. Using fast tract eligibility criteria for recovery all the patient had a score of 12 at $0 \mathrm{~min}$ and all of them had score of $>12$ at $15 \mathrm{~min}$ and $30 \mathrm{~min}$ and were ready to be shifted toward from the OR bypassing the post anaesthesia recovery room. CONCLUSION: Thus field block for inguinal hernia repair is a safe technique, that provides excellent quality and prolonged analgesia, with rapid recovery and minimal to nil complications.

KEYWORDS: Inguinal field block; excellent analgesia; rapid recovery.

INTRODUCTION: Hernia is the word derived from Greek words "Herons" an offshoot or bulge. It is defined by Sir Astley Cooper (1804) as "protrusion of any viscus or part of the viscus through an abnormal opening in the walls of its containing cavity. ${ }^{1}$

The performed choice of anaesthesia for all adult inguinal hernia repair is local, it is safe, simple, effective, and economical, without anaesthetic side effects. Further more local anaesthesia administered before the incision produces longer postoperative analgesia because local infiltration, theoretically inhibits build of local nociceptive molecules and therefore, there is better pain control in the postoperative period. ${ }^{2}$

Hernia repair can be performed under spinal, epidural, general and inguinal field block. Field block for inguinal hernia repair is the most cost-effective anaesthetic technique for out patients undergoing unilateral inguinal herniorrhaphy with respect to speed of recovery, 
patient comfort and associated incremental costs. ${ }^{3}$ These are not provided into a satisfactory level by the commonly employed techniques, such as general anaesthesia (GA) or centrineuraxial blockade. Hence to meet the above requirements the present study of field block for inguinal hernia repair is undertaken.

\section{OBJECTIVES:}

$>$ To evaluate the advantages of this field block for inguinal hernia repair.

$>$ To study the duration and quality of analgesia by using $1 \%$ lidocaine with adrenaline.

$>$ To study effects of inguinal field block with respect to speed of recovery \& patients comfort.

$>$ Other side effects pertaining to the inguinal field block.

\section{METHODOLOGY:}

$>$ A clinical study was undertaken 50 patients aged between 18-60 years posted for elective inguinal hernia repair, agreeing and co-operative for inguinal field block. Study was conducted at Chigateri General Hospital and Bapuji Hospital attached to J.J.M. Medical College, Davangere during the period of September 2005 to august 2007.

\section{$>$ Selection of patients:}

- Inclusion criteria: Adults between 18-60 years age belonging to American Society of Anesthesiologists (ASA) GradeI and ASA Grade II coming for elective inguinal hernia repair without any associated diseases.

- Exclusion criteria: Patients below 18 and above 60 years. Patients with ASA Grade III and ASA Grade IV.

Pre-anaesthetic evaluation was done a day prior to the elective surgery. Consent was obtained. Local anaesthetic test dose for Lidocaine was carried out on the previous day of surgery.

On the day of surgery an intravenous (IV) line was secured with no. 20 G IV Cannula. The monitors - pulseoximeter, ECG, Noninvasive Blood Pressure (NIBP) were connected. Premedication Inj. Midazolam $2 \mathrm{mg}$ IV was administered.

PROCEDURE OF FIELD BLOCK FOR INGUINAL HERNIA REPAIR: Under strict aseptic precautions with patient in supine position, a skin wheal is made just half an inch medial to the anterosuperior iliac spine(ASIP). A $23 \mathrm{G}$ spinal needle was fixed to a syringe containing $15 \mathrm{ml}$ of $1 \%$ lidocaine with adrenaline. The needle was then directed perpendicular to the skin through the skin wheal. The needle was placed just above transversalis fascia through which ilioinguinal nerve and iliohypogastric nerves traverse where $15 \mathrm{ml}$ of $1 \%$ lidocaine was injected in a fan shaped manner here.

A second wheal was made over the pubic tubercle (PT) and $5 \mathrm{ml}$ of $1 \%$ lidocaine with adrenaline was injected. A third skin wheal was raised $0.5 \mathrm{~cm}$ above the midpoint of the inguinal ligament (MPI) and $5 \mathrm{ml}$ of $1 \%$ lidocaine was injected to block genital branch of genitofemoral nerve. 
Then by using $10 \mathrm{ml}$ of $1 \%$ lidocaine a subcutaneous(SC) infiltration was done along the line of incision to block crossover fibres. The maximum dose of lidocaine with adrenaline to be given was $7 \mathrm{mg} / \mathrm{kg}$ which was kept in mind. A minimum of 10 minutes was allowed after the block, in this study. Whenever the patient complained of pain, at the neck of sac $2 \mathrm{ml}$ of $1 \%$ lidocaine with adrenaline administered. At the time of hernia repair a sedative dose of propofol was administered to all patients. In the present study the following scale was adopted to grade analgesia and relaxation.

1. Excellent: Patient comfortable, analgesia, and surgical relaxation adequate.

2. Good: Analgesia and relaxation adequate, minimal discomfort present during surgery alleviated by supplementary local anaesthetic agent at the neck of sac.

3. Fair: Analgesia and relaxation adequate, in addition to infiltration of the sac patients needed a narcotic supplementation.

4. Poor: Patients complaining of severe intolerable pain during surgery without relaxation and required GA.

Blood pressure, heart rate, oxygen saturation, ECG, monitoring were done every 5 minutes till the end of surgery. Duration of surgery and analgesia, were noted. The signs, symptoms of local anaesthetics toxicity were observed.

Then after the surgery post anaesthesia recovery was assessed in operation room by "criteria used to determine fast-track eligibility after ambulatory anaesthesia" (Table 1)and the postoperative pain relief and post-anaesthetic complications monitored.

The mentioned score is assessed for $30 \mathrm{~min}$, with interval of $15 \mathrm{~min}$ after the surgery. Once the patient achieves a score of 12 or more, patient is ready to be shifted directly towards bypassing the post anaesthesia recovery room.

The total duration of analgesia (the duration of onset of analgesia till the subjective compliant of pain) assessed in all the patients.

STATISTICAL ANALYSIS: Descriptive data included mean, standard deviation and percentage which were determined for the study group.

RESULTS: In our study majority of the patients were in age group of 18-30 years and 51-60 years, with mean age of 39 . All of them were males, maximum weight was $85 \mathrm{~kg}$ and minimum weight was $51 \mathrm{~kg}$, mean weight $60.74 \mathrm{kgs}$.

Out of 50 patients studied 16 had direct hernia and 34 had indirect hernia. Lidocaine with adrenaline used for field block, mean volume used $35.48 \mathrm{ml}$; maximum dose allowed $37 \mathrm{ml}$ and minimum dose allowed $35 \mathrm{ml}$.

36 patients had an excellent type of analgesia and relaxation. 8 patients complained of discomfort during surgical handling of the hernia repair. To alleviate this $2 \mathrm{ml}$ of $1 \%$ lidocaine with adrenaline was injected at the neck of the sac. 4 patients were not comfortable with the above measures and needed fentanyl depending upon their body weight. 2 patients had no analgesia at all, so GA was instituted.

Mean duration of surgery and analgesia was 39.54 and 201.02minute respectively. Two patients, who received GA, had no analgesia. 
No intraoperative complications. Analgesia and relaxation was Excellent in 72\%, Good $16 \%$, Fair in $8 \%$, poor in $4 \%$. Success rate $6 \%$, Failure rate $4 \%$.

Table 2 shows mean score and standard deviation for each parameter according to Criteria used to determine fast-track eligibility after ambulatory anaesthesia

Mean score and standard deviation of all 50 patients is shown in table 2. Mean score of 2 was obtained for physical activity, respiratory stability, haemodynamic stability, oxygen saturation status and post operative pain assessment.

Mean score of 1.96 was obtained for level of consciousness and post operative emetic symptoms, as 2 patients who received GA were arousable with minimal stimulation and 2 patients who received GA had transient vomiting or retching at 0 min respectively.

8 patients had a Fast track eligibility score of 12 at ' 0 ' $\mathrm{min}$, all of them had a score of $>12$ at ' 15 ' min and ' 30 ' min. All the patients were ready to be shifted to the ward bypassing the post anaesthesia recovery room.

DISCUSSION: Inguinal hernia repair is one of the most commonly encountered surgical correction in men representing $12.5 \%$ of total surgical repair in Britain. In providing anaesthesia for inguinal herniorrhaphy, the technique chosen must be most cost effective with respect to speed of recovery, patient comfort, and associated incremental costs. ${ }^{3}$

The advantage of local anesthesia are safety, simplicity, effectiveness, cost effective, low rate of recurrence and infection. ${ }^{5}$ It is a method of choice in outpatient surgery and for minimizing the cost of surgery.

Any patients with hernia, a field block will reduce the anaesthetic risk to a minimum, allow immediate ambulation and food intake, reduce postoperative complications such as urinary retention, atelectasis and phlebitis, and almost eliminate the need for post operative narcotic analgesia. ${ }^{6}$

Large series of studies are available in surgical and anaesthesia literature regarding the usage of field block for inguinal hernia repair. Most of these were with GA or neuraxial anesthesia or monitored anaesthesia care under deep sedation. But the search of literature does not reveal any studies which have utilized field block as a sole anaesthetic agent with lidocaine and adrenaline for inguinal hernia repair.

In view of the above, the present study was undertaken to investigate field block for inguinal hernia repair using $1 \%$ lidocaine with adrenaline. In the present study 50 patients of ASA class I and II posted for elective inguinal hernia repair were studied using the above technique.

Many authors have used lidocaine alone for inguinal field block 6, 7, but it is short acting. Followed by that, some authors added epinephrine to lidocaine for the block because epinephrine reduces plasma concentration of lidocaine, minimizes toxicity and also prolonged post operative pain relief. ${ }^{8}$

Some authors who used the above combination for institution of block found that there was an improvement in quality and duration of block. ${ }^{9}$ In surgical patients it may be postulated that ' $\mathrm{C}$ ' afferent fibers activity may be generated not only intraoperatively but also post operatively, partly as result of persistent inflammation and hyperalagesia at wound site which is affected by using lidocaine with adrenaline ${ }^{8}$ hence we have used the combination of lidocaine with adrenaline in our study. 
Table 3 shows the volume of lidocaine with adrenaline used in three studies. The present study was the combination of the above studies and utilized a mean volume $35.48 \mathrm{ml}$ of the drug.

DOSAGE AND CONCENTRATION OF LIDOCAINE WITH ADRENALINE: In our study we have used $1 \%$ lidocaine combine with adrenaline. It has been suggested that upper limit for lidocaine with adrenaline is $7 \mathrm{mg} / \mathrm{kg} .4$

As a fairly large volume of drug was required for the block, the concentration kept at $1 \%$ for lidocaine with adrenaline in our study.

The mean weight of our patients $60.74 \mathrm{~kg}$ and mean volume used is $35.48 \mathrm{ml}$, it become clear that the total dose of the lidocaine employed by us is well within the upper recommended limit.

QUALITY OF ANALGESIA AND RELAXATION: In the present study we graded 36 patients had excellent analgesia and relaxation, no supplementation is required during surgery. Only 8 patients had good analgesia and mild discomfort during sac manipulation which required supplementation. With additional infiltration around the neck of the sac with $2 \mathrm{ml}$ of lidocaine $1 \%$ with adrenaline, 4 patients had analgesia graded as fair with mild pain during surgery. These patients were given fentanyl $1-2 \mu \mathrm{g} / \mathrm{kg}$ to alleviate the pain. 2 patients (4\%) had severe intolerable pain during surgery, requiring conversion to GA.

It has been observed by various authors that at the time of traction on the sac, patients often complain of discomfort. 10,12 This finding was observed in 8 patients in our present clinical study.

Some authors used narcotic for pain relief during surgery. ${ }^{3,}{ }^{13}$ In the present study 4 patients require narcotics in additional to local anaesthetic supplementation.

A study stated that use of sedative dose of propofol has advantage of less nausea and vomiting, because of antiemetic action which in turn results in faster recovery and cost effectiveness. ${ }^{14}$

Some study stated that some sedation during the operation may be required for anxious patients which lose some of the benefits of avoiding GA. Patients who are excessively nervous may be unsuitable for surgery under local anaesthesia.11 In our study we used propofol at a dose of $25 \mathrm{mg}$ at the time of inguinal hernia repair. A study was conducted in 400 hernia patients who underwent surgery under local anaesthesia in whom $0.5 \%$ were converted to GA. ${ }^{15,16}$ In our study, 2 patients (4\%) required GA.

Epinephrine enhances the degree and extends the duration of lidocaine's peripheral nerve block. ${ }^{9}$ As per Covino et al $^{17}$, the duration of analgesic effect of lidocaine is 195 minutes \pm $26.3 \mathrm{~min}$ for brachial plexus block, for local infiltration $75 \mathrm{~min}$ (35-340 min), duration can be prolonged up to $20 \%$ by addition of epinephrine.

In the present study mean duration of analgesia was 201.02 minutes $(160 \mathrm{~min}$ $280 \mathrm{~min})$. So the present study correlates with studies done by Covino et al.

In a study author used 'fast track eligibility criteria' for all the patients leaving the operation room, to assess the recovery at every $30 \mathrm{~min}$ interval for meeting the criteria for discharge home from day surgery unit. ${ }^{3}$

So in our present study, we have used 'fast track eligibility criteria' for assessing post anaesthesia recovery after surgery for $30 \mathrm{~min}$ at every $15 \mathrm{~min}$ interval, to meet the criteria to shift the patients to ward bypassing the recovery room. 
Table 4 shows studies done by various authors for hernia repair under field block or monitored anaesthesia care as ambulatory anaesthesia.

All the patients after surgery were able to move all the four extremities with out any limitation of movements. The present study correlates Kark AE et al 1990.5 Since Local anaesthesia does not affect respiration and circulation Respiratory stability and Haemodynamic stability was maintained. During assessment 48 patients were awake and fully oriented, but two patients who received GA were arousable with minimal stimulation.

Oxygen saturation was $>90 \%$ in all the patients, 48 patients were pain free, but two patients who received GA complained of mild discomfort and 48 patients had no emetic symptoms but two patients who received GA had transient vomiting and retching at ' 0 ' minutes.

FAST TRACK ELIGIBILITY CRITERIA RECOVERY SCORE: All the patients had a score of 12 at ' 0 ' minute, all of them had a score of $>12$ at $15 \mathrm{~min}$ and $30 \mathrm{~min}$. All the patients were ready to be shifted toward bypassing the post anaesthesia recovery room, similar to the study done by Song D et al. ${ }^{3}$

SIDE EFFECTS PERTAINING TO THE INGUINAL FIELD BLOCK: In a study involving 41 patients who underwent inguinal hernia repair with local anaesthesia two complications were recorded. One patient developed wound infection, and one patient developed wound hematoma. ${ }^{22}$

In our study out of 50 patients who underwent inguinal hernia repair, no such complications were recorded.

CONCLUSION: Duration of analgesia was good by using 1\% lidocaine with adrenaline. Field block was found to be safe and fulfills the requirements of surgical relaxation with minimal alteration in physiological homeostasis. Lidocaine with adrenaline was effective for carrying out field block for inguinal hernia repair and provides long duration of post-operative pain relief. Field block is the best method as far as recovery profile is concerned. Field block for inguinal hernia repair avoids polypharmacy, is safe, economical, with rapid recovery when compared to neuraxial blockade and GA. Field block for inguinal hernia repair results in minimal or no complications. This technique can be used safely in patients with respiratory or cardiovascular diseases.

\section{BIBLIOGRAPHY:}

1. Kingsnorth, Bennett DH. Hernias, Umbillilus, Abdominal Wall Chapter 62. In : Short practice of surgery Bailey and Love. 23rd edn. 2000.p.1143.

2. Amid PK, Shulman AG. Local anaesthesia for inguinal hernia repair step by step procedure. Ann Surg 1994;220(6):735-737.

3. Song D, Greilich NB, White PF, Watcha MF, Tongier WK. Recovery profiles and costs of anaesthesia for outpatient unilateral inguinal herniorrhaphy. Anaesth Analg 2000;91:876-81.

4. Miller RD. Miller's Anaesthesia, JG Reves, Peter SA Glass, David A Lubarsky and Mathew D. McEvoy (edt), $6^{\text {th }}$ ed. Elsevier Churchill Living Stone. USA, 2005;1:345-350, 28-30pp.

5. Kark AE, Kurzer M, Waters KJ. Tension free mesh hernia repair : Review of 1098 cases using local anaesthesia in a day unit. Ann R Coll Surg Engl 1995;77:299-304.

6. Prevoznik. Useful blocks in outpatient anaesthesia in international anaesthesiology. Clinic Kurt F. Schmidt 4 edn, 1976;2:91-95. 
7. Young DV. Comparison of local, spinal and general anaesthesia for inguinal herniorrhaphy. Am J Surg 1987; 153:560-563.

8. Dierking GW, Dahl JB, Kastrup J, Dahl A, Kehlet H. Effect of pre-vs post operative inguinal field block on postoperative pain after herniorrhaphy. Br J Anaesth 1992;68:344-348.

9. Sinnot JC, Cogswell LP, Johnson A, Sirichartz GR. On the mechanism by which epinephrine potentiates lidocaine's peripheral nerve block. Anaesthesiology 2003;98:181-188.

10. Earle AS. Local anaesthesia for inguinal herniorrhaphy. Am J Surg 1960;100:782-786.

11. Dunn J, Day CJE. Local anaesthesia for inguinal and femoral hernia repair update in anaesthesia for Inguinal and Femoral Hernia Repair. 1994;4Article 6:1-2.

12. Tverjkoy M, Cozacovc, Ayache M, Bradley EL, Kissin I. Post operative pain after inguinal herniuorrhaphy with different type of anaesthesia. Anesth Analg 1990;70:29-35.

13. Zoilinger RM, Konstantakos AK, Stellato TA, Hirgchfeld SS. Local anaesthesia plus deep sedation for adult inguinal hernia repair in an ambulatory surgery. Springlink-Journal article, Hernia 1998;2(2):77-80.

14. Marshall SI, Chung F. Discharge criteria and complication after ambulatory surgery. Anaesth Analg 1999;88:508-517.

15. Callesen T, Kehlet H. Post herniorrhaphy pain. Anaesthesiol 1997;87:1219-1230.

16. Callesen T, Beck K, Kehlet $H$. The feasibility, safety and cost of infiltration anaesthesia for hernia repair. Anaesthesiology 1998;53:31-35.

17. Covino, Benjamin G, Heleng, Vasalio. Clinical aspect of Local anaesthesia. Chapter 4, Local anaesthetic mechanism of action and clinical use. Published by Grane and Stralioninc New York 1976:58-59

18. Ding Y, White PF. Post-Herniorrhaphy pain in outpatients after pre-incision ilioinguinal hypogastric nerve block during monitored anaesthesia care. Can J Anaesth 1995;42(1):12-15.

19. Gianetta E, Cuneo S, Vitale B, Camerini G, Marini P, Stella M. Anterior tension-free repair of recurrent inguinal hernia under local anaesthesia. Ann Surg 1999;231(1):132-136.

20. Apfubaum JL, Walawander CA, Grasela TH, Wise PBS, McLeskey C, Roizen MF et al. Eliminating intensive postoperative care in same-day surgery patients using shortacting anaesthetics. Anaesthesiology 2002;97:66-74.

21. Ma H, Tang J, White PF, Zaentz A, Wender RH, Sloninsky A et al. Perioperative rofecoxib improves early recovery after outpatient herniorrhaphy. Anaesth Analg 2004;98:970975.

22. Prado E, Herrera MF, Letay FV. Inguinal herniorrhaphy under local anesthesia : a study of introperative tolerance. Am Surg 1994;60(8):617-619. 
TABLE 1: CRITERIA USED TO DETERMINE FAST-TRACK ELIGIBILITY AFTER AMBULATORY ANAESTHESIA ${ }^{4}$

\begin{tabular}{|c|c|c|}
\hline Criteria & & Score \\
\hline \multirow{3}{*}{ Physical activity } & Able to move all extremities on command & 2 \\
\hline & Some weakness in movement of the extremities & 1 \\
\hline & Unable to voluntarily move the extremities & 0 \\
\hline \multirow{3}{*}{ Respiratory stability } & Able to breathe deeply & 2 \\
\hline & Tachypnoea with good cough & 1 \\
\hline & Dyspnoeic with weak cough & 0 \\
\hline \multirow{3}{*}{$\begin{array}{l}\text { Hemodynamic } \\
\text { Stability }\end{array}$} & Blood pressure $<15 \%$ of the baseline MAP value & 2 \\
\hline & $\begin{array}{l}\text { Blood pressure between } 15 \% \text { and } 30 \% \text { of the baseline MAP } \\
\text { value }\end{array}$ & 1 \\
\hline & Blood pressure $>30 \%$ below the baseline MAP value & 0 \\
\hline \multirow{3}{*}{$\begin{array}{ll}\text { Level } & \text { of } \\
\text { Consciousness }\end{array}$} & Awake and oriented & 2 \\
\hline & Arousable with minimal stimulation & 1 \\
\hline & Responsive only to tactile stimulation & 0 \\
\hline \multirow{3}{*}{$\begin{array}{l}\text { Oxygen Saturation } \\
\text { Status }\end{array}$} & Maintains value $>90 \%$ on room air & 2 \\
\hline & Requires supplemental oxygen (nasal prongs) & 1 \\
\hline & Saturation $<90 \%$ with supplemental oxygen & 0 \\
\hline \multirow{3}{*}{$\begin{array}{l}\text { Postoperative Pain } \\
\text { Assessment }\end{array}$} & None or mild discomfort & 2 \\
\hline & Moderate to severe pain controlled with IV analgesics & 1 \\
\hline & Persistent severe pain & 0 \\
\hline \multirow{3}{*}{$\begin{array}{l}\text { Postoperative emetic } \\
\text { symptoms }\end{array}$} & None or mild nausea with no active vomiting & 2 \\
\hline & Transient vomiting or retching & 1 \\
\hline & Persistent moderate to severe nausea and vomiting & 0 \\
\hline Total score & & 14 \\
\hline
\end{tabular}


TABLE 2: RECOVERY SCALE

\begin{tabular}{|l|l|l|l|l|l|l|}
\hline \multicolumn{1}{|c|}{ Parameter } & 0 minutes & \multicolumn{2}{l|}{15 minutes } & \multicolumn{2}{l|}{30 minutes } \\
\cline { 2 - 7 } & $\begin{array}{l}\text { Mean } \\
\text { Score }\end{array}$ & $\begin{array}{l}\text { Standard } \\
\text { deviation }\end{array}$ & $\begin{array}{l}\text { Mean } \\
\text { score }\end{array}$ & $\begin{array}{l}\text { Standard } \\
\text { deviation }\end{array}$ & $\begin{array}{l}\text { Mean } \\
\text { score }\end{array}$ & $\begin{array}{l}\text { Standard } \\
\text { deviation }\end{array}$ \\
\hline PHYSICAL ACTIVITY & 2 & 0 & 2 & 0 & 2 & 0 \\
\hline $\begin{array}{l}\text { RESPIRATORY } \\
\text { STABILITY }\end{array}$ & 2 & 0 & 2 & 0 & 2 & 0 \\
\hline $\begin{array}{l}\text { HAEMODYNAMIC } \\
\text { STABILITY }\end{array}$ & 2 & 0 & 2 & 0 & 2 & 0 \\
\hline $\begin{array}{l}\text { LEVEL OF } \\
\text { CONSCIOUSNESS }\end{array}$ & 1.96 & 0.2 & 1.96 & 0.2 & 1.98 & 0.14 \\
\hline $\begin{array}{l}\text { OXYGEN } \\
\text { SATURATION } \\
\text { STATUS }\end{array}$ & 2 & 0 & 2 & 0 & 2 & 0 \\
\hline $\begin{array}{l}\text { POST OPERATIVE } \\
\text { PAIN ASSESSMENT }\end{array}$ & 2 & 0 & 2 & 0 & 2 & 0 \\
\hline $\begin{array}{l}\text { POST OPERATIVE } \\
\text { EMETIC SYMPTOMS }\end{array}$ & 1.96 & 0.2 & 2 & 0 & 2 & 0 \\
\hline TOTAL SCORE & 13.92 & 0.396 & 13.96 & 0.198 & 13.98 & 0.141 \\
\hline
\end{tabular}

TABLE 3: VOLUME OF LIDOCAINE WITH ADRENALINE USED IN THREE STUDIES

\begin{tabular}{|l|l|l|l|l|l|l|}
\hline Study & Total volume & ASIP & MPI & PT & SC & $\begin{array}{l}\text { Neck of the } \\
\text { sac }\end{array}$ \\
\hline${\text { Earle AS }(1960)^{10}}^{34-40 \mathrm{ml}(0.5 \%)}$ & $\begin{array}{l}5- \\
10 \mathrm{ml}\end{array}$ & - & $3.5 \mathrm{ml}$ & $\begin{array}{l}5- \\
20 \mathrm{ml}\end{array}$ & $2 \mathrm{ml}$ \\
\hline $\begin{array}{l}\text { Dierking et al } \\
(1992)^{8}\end{array}$ & $\begin{array}{l}55 \mathrm{ml}(15-\mathrm{ml} 1 \%+40 \mathrm{ml} \\
0.5 \%)\end{array}$ & $25 \mathrm{ml}$ & $5 \mathrm{ml}$ & $5 \mathrm{ml}$ & $20 \mathrm{ml}$ & - \\
\hline $\begin{array}{l}\text { Dunn J et al } \\
(1994)^{11}\end{array}$ & $\begin{array}{l}42 \mathrm{ml}(1 \%) \\
(60-70 \mathrm{~kg})\end{array}$ & - & - & - & - & - \\
\hline Present study & $35-37 \mathrm{ml}$ & $15 \mathrm{ml}$ & $5 \mathrm{ml}$ & $5 \mathrm{ml}$ & $10 \mathrm{ml}$ & $2 \mathrm{ml}$ \\
\hline
\end{tabular}


TABLE 4: VARIOUS STUDIES FOR HERNIA REPAIR UNDER FIELD BLOCK OR MONITORED ANAESTHESIA

\begin{tabular}{|l|l|l|l|}
\hline Year & Study & Procedure & Result \\
\hline 1994 & Ding Y et al ${ }^{18}$ & $\begin{array}{l}\text { MAC with field } \\
\text { block }\end{array}$ & $\begin{array}{l}\text { Ambulation time 86 } \pm 18 \text { minutes } \\
\text { Fit for discharge 112 } \pm 49 \text { minutes }\end{array}$ \\
\hline 1995 & Kark AE et al ${ }^{5}$ & Field block & $\begin{array}{l}\text { Able to walk to the room assisted by nurse after 1.5 } \\
\text { hrs but fully able to walk within 3 hours. } \\
\text { Post-operative wound pain 1\%, Haematoma 1\%, } \\
\text { Urinary retention nil. }\end{array}$ \\
\hline 2000 & Ezio G et al ${ }^{19}$ & Local anesthesia & Hospital stay ranges 3 hrs to 14 days. \\
\hline 2000 & Song D et al ${ }^{3}$ & $\begin{array}{l}\text { IHNB-MAC } \\
\text { propofol }\end{array}$ & $\begin{array}{l}\text { All patients were transferred directly from } \\
\text { operation room to phase II recovery unit. }\end{array}$ \\
\hline 2002 & $\begin{array}{l}\text { Apfulbaum JL } \\
\text { et al }{ }^{20}\end{array}$ & $\begin{array}{l}\text { MAC with field } \\
\text { block }\end{array}$ & $\begin{array}{l}\text { Mean 90 minutes as a recovery time. } \\
\text { Recovery range 20 minutes to 210 minutes. } \\
\text { General anaesthesia: 90 minutes to 270 minutes. }\end{array}$ \\
\hline 2004 & Hangma et al 21 & $\begin{array}{l}\text { Field block }+ \\
\text { Propofol }\end{array}$ & The details are given below : \\
\hline
\end{tabular}

